\title{
Exposição ocupacional ao calor em atividades a céu aberto na construção de estruturas de edifícios
}

\author{
Occupational heat exposure in outdoor activities in \\ building structures
}

\section{Adriana Eloá Bento Amorim \\ Lucila Chebel Labaki \\ Paulo Alves Maia \\ Thais Maria Santiago Barros \\ Luiz Roberto Monteiro}

\section{Resumo}

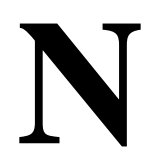

a construção civil a excessiva exposição ao calor pode causar sobrecarga térmica e danos à saúde do trabalhador. Este estudo apresenta uma análise da exposição ao calor de 64 trabalhadores que desenvolvem atividades sobre lajes de concreto em construção de estruturas de concreto em edifícios. Para tanto, utiliza-se o índice de bulbo úmido termômetro de globo (IBUTG), obtido a partir das temperaturas de bulbo úmido natural, de bulbo seco e de globo, medidas sobre as lajes, e analisado em conjunto com taxas metabólicas estimadas para cada função de trabalho, conforme as normas da International Standardization for Organization (ISO). A avaliação foi feita de acordo com os critérios da legislação brasileira, aplicando-se a Norma Regulamentadora No 15 (NR-15), do Ministério do Trabalho. Os resultados demonstram que há necessidade de gerenciamento e adoção de medidas de controle, em especial de pausas para descanso térmico visando ao resfriamento corporal para evitar doenças oriundas do calor. Conclui-se que, como o número de horas de pausa para recuperação térmica é significativo em relação ao número de horas totais de trabalho medidas (39\% para atividades pesadas e 20\% para atividades moderadas), o regime trabalho/descanso adequado tem potencial para afetar o ritmo de trabalho na construção civil.

${ }^{1}$ Adriana Eloá Bento Amorim ${ }^{1}$ Universidade Estadual de Campinas Campinas - SP - Brasil

${ }^{2}$ Lucila Chebel Labaki ${ }^{2}$ Universidade Estadual de Campinas Campinas - SP - Brasil

${ }^{3}$ Paulo Alves Maia ${ }^{3}$ FUNDACENTRO Campinas - SP - Brasil

${ }^{4}$ Thais Maria Santiago de Moraes Barros 4FUNDACENTRO Campinas - SP - Brasil

${ }^{5}$ Luiz Roberto Monteiro ${ }_{5}^{5}$ FUNDACENTRO Campinas - SP - Brasil

Recebido em 11/03/19/ Aceito em 12/08/19
Palavras-chave: Exposição ao calor. Atividades a céu aberto. Pausas no trabalho. Construção civil.

\section{Abstract}

In the construction industry, excessive heat exposure may cause thermal overload and damage workers' health. This study presents an analysis of the heat exposure of sixty-four workers performing activities on concrete slabs in the construction of concrete structures in buildings. In order to do that, the Wet Bulb Globe Temperature (WBGT) obtained from temperatures of natural with estimated metabolic rates was used for each work function, according to standards from International Standardization for Organization (ISO). The evaluation was made using criteria set by Brazilian laws, applying the Regulatory Standard Number 15 from the Ministry of Labour. The results showed there is a need to manage and adopt control measures, especially thermal rest breaks, aimed at body cooling to avoid diseases caused by heat. The study concluded that as the number of hours of thermal recovery rest is significant in relation to the number of total hours of work measured (39\% for heavy activities and $20 \%$ for moderate activities), the adequate work/rest scheme can potentially affect the work pace in construction.

Keywords: Heat exposure. Outdoor activities. Rest at work. Civil construction. wet bulb, dry bulb and black globe, measured on the slabs and analysed along

AMORIM, A. E. B.; LABAKI, L. C.; MAIA, P. A.; BARROS, T. M. S.; MONTEIRO, L. R. Exposição ocupacional ao calor em atividades a céu aberto na construção de estruturas de edifícios. Ambiente Construído, Porto Alegre, v. 20, n. 1, p. 231-245, jan./ mar. 2020.

ISSN 1678-8621 Associação Nacional de Tecnologia do Ambiente Construído.

http:/ / dx. doi. org/ 10.1590/ s1678-86212020000100371 


\section{Introdução}

As mudanças climáticas, assim como ocorre com o meio ambiente, geram efeitos significativos sobre a saúde humana. Esses efeitos podem ser ainda maiores em trabalhadores que desenvolvem suas tarefas ao ar livre e encontram-se na maior parte do tempo diretamente expostos às variáveis ambientais.

Condições ambientais desfavoráveis, como temperaturas elevadas combinadas ao esforço físico decorrente de atividades laborais e vestimentas inadequadas, podem elevar a temperatura interna do corpo humano (termorregulação), causando ativação das glândulas sudoríparas, vasodilatação, desidratação, câimbras, choque térmico ou insolação, entre outros. Esses sintomas e doenças são frequentes quando a exposição ao calor atinge níveis críticos, pois podem levar o corpo humano a uma condição de sobrecarga térmica, que, se prolongada, causa uma série de sintomas e reações fisiológicas denominadas estresse térmico (GUYTON, 1993; KROEMER; GRANDJEAN, 2005; AMERICAN..., 2010; CAMARGO; FURLAN, 2011). Indiretamente, a exposição ao calor excessivo pode resultar em acidentes do trabalho, devido a níveis mais altos de fadiga, lapsos de concentração e tomadas de decisão erradas (MORABITO et al., 2014; JIA; ROWLINSON; CICCARELLI, 2016).

Segundo Calvert et al. (2013), as indústrias com maiores taxas de exposições ao calor em trabalhos potencialmente perigosos a céu aberto são as da agricultura (85\%), da construção civil (73\%) e da mineração (65\%).

Na indústria da construção civil brasileira, representada por cerca de 1,8 milhão de trabalhadores formais (BRASIL, 2017a), os sistemas construtivos são predominantemente convencionais e envolvem complexos processos de gestão, o que dificulta o controle da segurança e do meio ambiente de trabalho. Os trabalhadores ficam sujeitos a várias situações de exposição ao calor nas etapas das obras, pois muitas atividades são realizadas a céu aberto, fazendo-se necessárias medidas de controle para evitar o adoecimento.

Entre as atividades a céu aberto em que há maior exposição dos trabalhadores ao calor ambiental na construção de edifícios de multipavimentos destaca-se a execução de estruturas de concreto em serviços de carpintaria, armação e concretagem. Em alguns empreendimentos é prevista a execução de alvenaria no pavimento de cobertura e respectiva platibanda nas lajes de cobertura, onde são instalados reservatórios, casas de máquinas e telhados.

Chan et al. (2012) destacaram que, apesar de a literatura internacional ser abundante em notas de orientação geral sobre os riscos de estresse por calor, há falta de pesquisa científica específica para a indústria da construção civil que apresente medidas de segurança de combate ao estresse térmico com base em parâmetros clínicos e técnicos confiáveis.

Nesse contexto, este trabalho apresenta uma avaliação da exposição ocupacional ao calor de trabalhadores em atividades desenvolvidas a céu aberto na etapa de execução de estruturas de concreto armado em edifícios, por meio da análise do índice de bulbo úmido termômetro de globo (IBUTG), obtido conjuntamente com taxas metabólicas estimadas para cada atividade. O estudo foi registrado no Comitê de Ética em Pesquisa da Universidade Estadual de Campinas, São Paulo, Brasil (CAEE 64413717.7.00005404).

\section{Referencial teórico}

O estudo sobre a exposição ocupacional ao calor é amplo, sendo, portanto, destacados alguns tópicos essenciais para o entendimento da avaliação dessa exposição em atividades a céu aberto na construção civil.

\section{Normas brasileiras de exposição ao calor}

Normas brasileiras de segurança e saúde do trabalho determinam a obrigatoriedade de medidas protetivas contra a exposição aos riscos presentes nos locais de trabalho. Além da Norma Regulamentadora N N $^{\circ}$ (NR9) (BRASIL, 2017b), que estabelece a necessidade de um programa de prevenção de riscos ambientais, e da NR-15 (BRASIL, 2018a), que trata de atividades e operações insalubres (mais especificamente do Anexo 3, que trata da exposição ocupacional ao calor), tem-se a NR-21 (BRASIL, 1999), referente às condições de trabalho a céu aberto. A NR-21 prevê a instalação de abrigos contra intempéries, o uso de equipamentos de proteção e outras medidas especiais para proteção dos trabalhadores contra insolação, frio extremo, vento e umidade, que prejudicam a saúde. Essas normas, porém, não especificam o tipo de medida protetiva para os trabalhadores expostos diretamente ao calor. 
A norma específica de saúde e segurança no trabalho para a construção civil, a NR-18, Condições e Meio Ambiente de Trabalho na Indústria da Construção (BRASIL, 2018b), exige a elaboração e implantação de um programa de prevenção de riscos (PCMAT) que contemple as exigências da NR-9 e da NR-15, a instalação de cobertura nos setores de carpintaria e armações de ferragens, e prevê o uso de equipamentos de proteção individual, atendendo às exigências da NR-6, Equipamento de Proteção Individual (BRASIL, 2018c). A inobservância dessas normas tem gerado ocorrências de doenças do calor e acidentes do trabalho, além de prejuízos financeiros das empresas relacionados com multas e indenizações trabalhistas.

\section{Índice de avaliação da exposição ao calor}

Para a avaliação da exposição ao calor nos ambientes de trabalho, o IBUTG é o índice mais utilizado internacionalmente (OCCUPATIONAL..., 1999; PARSONS, 2006, 2013), inclusive no Brasil. Para a determinação de condições de insalubridade, esses valores são comparados com limites de tolerância. Estes representam os limites de tolerância máximo e mínimo a que a maioria dos trabalhadores pode estar exposta ao agente ambiental sem que isso cause danos à saúde durante a vida laboral.

No cálculo do IBUTG são levados em conta três tipos de variáveis: temperatura de bulbo seco (Tbs) ou temperatura do ambiente; temperatura de bulbo úmido natural (Tbn), que representa o efeito das trocas de calor por evaporação e convecção; e temperatura de globo (Tg), que representa o efeito das trocas de calor por radiação e convecção. O IBUTG em ambiente externo com carga solar é dado pela Equação 1 da ISO 7243 (INTERNATIONAL..., 2017).

IBUTG $=0,7 \mathrm{Tbn}+0,2 \mathrm{Tg}+0,1 \mathrm{Tbs}$

Eq. 1

Conforme a NR-15, a determinação da condição de insalubridade é feita através da análise de intervalos de IBUTG, ou limites de tolerância, em conjunto com os tipos de atividades leve, moderada e pesada. Os tipos de atividade são determinados por faixas de taxa metabólica gerada na atividade, conforme o Quadro 1 (BRASIL, 2018a).

A ISO 8996 (INTERNATIONAL..., 2004) recomenda a estimativa da taxa metabólica, em maior ou menor nível de precisão, para cada situação de exposição. Essa estimativa foi feita por meio do método de decomposição do movimento descrito nessa norma.

Para exposição ao calor em determinada faixa de IBUTG e tipo de atividade, a NR-15 (BRASIL, 1978) determina um regime de trabalho intermitente, no qual períodos de trabalho e de descanso térmico são intercalados, conforme o Quadro 2.

\section{Quadro 1 - Taxas de metabolismo por tipo de atividade}

\begin{tabular}{|l|c|}
\hline \multicolumn{1}{|c|}{ TIPO DE ATIVIDADE } & kcal/hora \\
\hline EM REPOUSO & 100 \\
\hline TRABALHO LEVE & 125 \\
\hline De pé, trabalho leve, em máquina ou bancada, principalmente com os braços & 150 \\
\hline Sentado, movimentos moderados com braços e pernas (ex.: dirigir) & 150 \\
\hline Sentado, movimentos moderados com braços e tronco (ex.: datilografia) & \\
\hline TRABALHO MODERADO & 180 \\
\hline Sentado, movimentos vigorosos com braços e pernas & 175 \\
\hline De pé, trabalho leve em máquina ou bancada com alguma movimentação & 220 \\
\hline De pé, trabalho moderado em máquina ou bancada com alguma movimentação & 300 \\
\hline Em movimento, trabalho moderado de levantar ou empurrar & \\
\hline TRABALHO PESADO & 440 \\
\hline Trabalho intermitente de levantar, empurrar ou arrastar pesos (ex.: remoção com pá) & 550 \\
\hline Trabalho fatigante & \\
\hline
\end{tabular}

Fonte: adaptado do Anexo 3 da NR15 (BRASIL, 2018a). 
Quadro 2 - Limites de tolerância ao calor para exposição em regime de trabalho/descanso (RTD) no próprio local de trabalho

\begin{tabular}{|l|c|c|c|}
\hline \multicolumn{1}{|c|}{$\begin{array}{c}\text { REGIME DE TRABALHO } \\
\text { INTERMITENTE COM } \\
\text { DESCANSO NO PRÓPRIO LOCAL } \\
\text { DE TRABALHO (por hora) }\end{array}$} & LEVE & MODERADA & PESADA \\
\cline { 2 - 4 } & Até 30,0 & Até 26,7 & Até 25,0 \\
\hline Trabalho contínuo & 30,1 a 30,6 & 26,8 a 28,0 & 25,1 a 25,9 \\
\hline $\begin{array}{l}45 \text { min trabalho } \\
15 \text { min descanso }\end{array}$ & 30,7 a 31,4 & 28,1 a 29,4 & 26,0 a 27,9 \\
\hline $\begin{array}{l}30 \text { min trabalho } \\
30 \text { min descanso }\end{array}$ & 31,5 a 32,2 & 29,5 a 31,1 & 28,0 a 30,0 \\
\hline $\begin{array}{l}15 \text { min trabalho } \\
45 \text { min descanso }\end{array}$ & Acima de 32,2 & Acima de 31,1 & Acima de 30,0 \\
\hline $\begin{array}{l}\text { Não permitido o trabalho sem a adoção } \\
\text { de medidas adequadas de controle }\end{array}$ &
\end{tabular}

Fonte: adaptado do Anexo 3 da NR-15 (BRASIL, 2018a).

A estimativa de taxa metabólica para cada categoria profissional pode ser obtida utilizando-se o método 2A Observação, conhecido como método de composição de movimentos, proposto pela norma ISO 8996 (INTERNATIONAL..., 2004), com o auxílio do software Conforto 2.03 (RUAS, 2002). Segundo esse método, o ciclo de trabalho de cada trabalhador, composto pelas tarefas de maior solicitação em termos de calor, foi estabelecido. A seguir, cada tarefa desse ciclo foi observada com a finalidade de decompor os movimentos do corpo necessários a sua realização e de medir sua duração (ti). Aos movimentos de cada membro do corpo é adotado um valor de calor metabólico padrão (Mi). A soma do calor metabólico resultante dos movimentos de todos os membros durante o período dos 60 min de maior exposição térmica foi considerada como taxa de calor metabólico da atividade (M), que pode ser dada em termos de equivalente metabólico (met), watts (W) ou quilocalorias por hora (kcal/h). Assim, a taxa metabólica média (M) de cada tarefa por ciclo de trabalho é dada pela Equação 2 da ISO 8996 (INTERNATIONAL..., 2004).

$M=\frac{1}{T} \sum_{i=1}^{n} M i * t i$

Onde:

Mi é taxa metabólica média ponderada da tarefa em um ciclo de trabalho, em $\mathrm{W} / \mathrm{m}^{2}$;

ti é duração da tarefa i, em minutos; e

T é tempo de exposição ou período para um ciclo de trabalho (60 min).

\section{Impactos da exposição ao calor na construção civil}

Diversas pesquisas discutiram os impactos das pausas de descanso no ritmo de trabalho ou produtividade na indústria da construção civil. Embora muitos estudos tenham apontado que o desempenho humano e a produção dependem do ambiente térmico, não determinaram uma relação direta entre a produtividade e os parâmetros climáticos, de atividades e pessoais (SRINAVIN; MOHAMED, 2003).

A pesquisa de Wong et al. (2014) permitiu estimar a taxa metabólica média de armadores expostos a céu

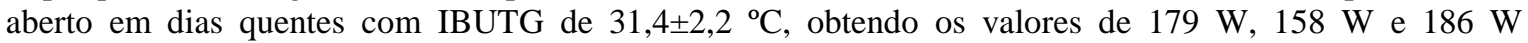
respectivamente nas tarefas de corte, dobra e fixação de armações de aço em canteiros de obra.

Yi e Chan (2015) mostraram a ocorrência de reações fisiológicas causadas pela incapacidade do corpo de manter a temperatura interna em torno de $37^{\circ} \mathrm{C}$ ou estresse térmico quando causada pelo calor nas atividades de armação de aço e concretagem de lajes de edifícios em Hong Kong, China. Os valores IBUTG atingiram de $25,9 \pm 1,0^{\circ} \mathrm{C}$ a $33,7 \pm 1,7^{\circ} \mathrm{C}$ respectivamente. Para garantir um cronograma com taxa diária de trabalho contínuo de $87,8 \%$ em jornada de trabalho de 9 h, os pesquisadores propuseram a implantação de intervalos de descanso térmico de $20 \mathrm{~min} / \mathrm{h}$ pela manhã e de $30 \mathrm{~min} / \mathrm{h}$ pela tarde, além do intervalo das $12 \mathrm{~h}$ às $13 \mathrm{~h}$ para o almoço.

A relação entre a exposição ao calor e o ritmo de produção de 16 operários nos canteiros de obra foi estudada por Li et al. (2016). Os autores levaram em conta os valores do IBUTG e os fatores pessoais idade, sexo, peso, altura, índice de massa corpórea e tempo de serviço. O estudo concluiu que, quando o IBUTG aumentava 1 
${ }^{\circ} \mathrm{C}$, a porcentagem de tempo de trabalho contínuo decrescia $0,57 \%$ e a porcentagem de tempo de descanso aumentava $0,74 \%$.

No Japão, Morioka, Miyai e Miyashita (2006) analisaram o IBUTG, os fatores fisiológicos e a frequência de ingestão de água antes e depois da jornada de trabalho de 12 operários da construção de uma usina hidrelétrica. O IBUTG variou entre $23{ }^{\circ} \mathrm{C}$ e $34{ }^{\circ} \mathrm{C}$, e constataram baixa ingestão de água. Assim, propuseram um cronograma com pausas de $20 \mathrm{~min} / \mathrm{h}$ para melhorar os índices de desconforto no verão.

Como medidas importantes para atenuar os efeitos da exposição ao calor, além do monitoramento diário e de pausas para recuperação térmica, tem-se o uso de roupas com isolamento térmico recomendado pela ISO 9920 (INTERNATIONAL..., 2009) e de protetores solares combinados com uma hidratação adequada.

\section{Método de pesquisa}

O estudo foi realizado em seis diferentes obras de construção de edifícios no período de março de 2017 a março de 2018, abrangendo as quatro estações do ano e perfazendo um total de 33 dias de medição, no horário das $7 \mathrm{~h}$ às $16 \mathrm{~h}$, e de $297 \mathrm{~h}$ de medição (inclusive horas de almoço). Foram observadas as atividades a céu aberto realizadas em 14 lajes de concreto armado, em diferentes alturas de trabalho, variando de 4,8 m a 46,4 m do piso térreo. Essas medidas serviram para calcular a taxa de metabolismo média de armadores, carpinteiros, pedreiros e ajudantes. As medidas de IBUTG foram obtidas em 17 lajes de concreto. A análise da situação térmica nas 17 lajes foi determinada utilizando-se o metabolismo médio de cada categoria profissional e a exposição de calor, dada pelo IBUTG médio, de cada categoria. Os operários observados por atividades em cada laje e por subperíodo de medição são representados no Quadro 3.

As obras estão localizadas na cidade de Campinas, estado de São Paulo, Brasil. A coleta de dados ocorreu nos empreendimentos onde houve permissão dos proprietários e em lajes que possibilitavam o acesso após a concretagem.

As datas de medição foram determinadas em função da disponibilidade das construtoras, do cronograma de concretagem das lajes e da presença de, no mínimo, dois pesquisadores em dias de condições climáticas favoráveis. Em lajes recém-concretadas a coleta ocorreu em pelo menos dois dias após a cura.

As atividades observadas consistiram na montagem de pilares, vigas e escoramentos para lajes, assim como na execução de estruturas e alvenaria para a construção de reservatórios e platibandas nas lajes de cobertura.

Participaram do estudo 64 trabalhadores do sexo masculino, sendo 33 (52\%) carpinteiros, 13 (20\%) armadores, 4 (6\%) pedreiros e 14 (22\%) ajudantes. A média de idade foi de 40,1士11,3 anos, a massa corporal média, de $74,0 \pm 8,9 \mathrm{~kg}$, e altura média, de $169 \pm 6 \mathrm{~cm}$.

Para a obtenção da temperatura de bulbo úmido, temperatura de bulbo seco e temperatura de globo utilizouse de medidores automáticos de exposição ao calor, o QuesTemp 36, com datalogger e precisão $\pm 0,5{ }^{\circ} \mathrm{C}$, posicionado sobre as lajes a 1,20 m do piso (Figura 1). Antes, porém, os equipamentos foram calibrados e passaram por uma aferição para ajustar os valores aos de equipamentos convencionais de termômetros de mercúrio (precisão de $\pm 0,1^{\circ} \mathrm{C}$ ), conforme descrito em Amorim et al. (2018).

As temperaturas (Tbn, Tbs e Tg) foram registradas de 1 em 1 min, no período das $7 \mathrm{~h}$ às $16 \mathrm{~h}$, embora a jornada de trabalho se estendesse até as $17 \mathrm{~h}$, perfazendo $9 \mathrm{~h}$ de real exposição ao calor, uma delas reservada para o almoço, das $11 \mathrm{~h}$ às $12 \mathrm{~h}$ (horário observado na maioria das obras). O IBUTG foi calculado através da Equação 1 .

As médias e medianas horárias para cada dia de exposição foram calculadas para compará-las com os limites de tolerância de exposição ao calor estabelecidos pela NR-15 (BRASIL, 1978). O valor médio das 9 h, por exemplo, contabilizou valores de IBUTG, minuto a minuto, medidos das $8 \mathrm{~h} 01 \mathrm{~min}$ às $9 \mathrm{~h}$. 
Quadro 3 - Atividades registradas e operários observados por laje, por subperíodo de medição (Continua...)

\begin{tabular}{|c|c|c|c|}
\hline $\begin{array}{l}\text { Laje/ } \\
\text { Obra/ } \\
\text { Altura }\end{array}$ & Subperíodos & Atividades observadas & $\begin{array}{l}\text { Operários } \\
\text { observados }\end{array}$ \\
\hline $\begin{array}{l}\text { L1 } \\
\text { Obra } 1 \\
\mathrm{H}=7,2 \mathrm{~m}\end{array}$ & $\begin{array}{l}\text { 10/11/13/16/17/e/18/ } \\
\operatorname{mar} / 17\end{array}$ & $(1)$ & $(1)$ \\
\hline \multirow{2}{*}{$\begin{array}{l}\mathrm{L} 2 \\
\text { Obra } 2 \\
\mathrm{H}=16,6 \mathrm{~m}\end{array}$} & \multirow[b]{2}{*}{ 22/23/24/mar/17 } & $\begin{array}{l}\text { Colocação das armações de aço nas fôrmas das } \\
\text { vigas da laje de cobertura }\end{array}$ & 03 armadores \\
\hline & & $\begin{array}{l}\text { Retirada/desmontagem de fôrmas de pilares. } \\
\text { Montagem de fôrmas de pilares para } \\
\text { reservatório da cobertura }\end{array}$ & $\begin{array}{l}04 \text { carpinteiros } \\
01 \text { ajudante (geral) }\end{array}$ \\
\hline \multirow{3}{*}{$\begin{array}{l}\text { L3 } \\
\text { Obra } 3 \\
\mathrm{H}=23,6 \mathrm{~m}\end{array}$} & \multirow{3}{*}{ 02/03/04/mai/17 } & $\begin{array}{l}\text { Montagem de fôrmas de pilares e vigas da laje } \\
\text { do } 6^{\circ} \text { pavimento }\end{array}$ & 06 carpinteiros \\
\hline & & $\begin{array}{l}\text { Colocação das armações de aço nas fôrmas de } \\
\text { pilares e vigas do } 6^{\circ} \text { pavimento }\end{array}$ & 02 armadores \\
\hline & & Transporte de fôrmas e de armações de aço & 04 ajudantes (geral) \\
\hline \multirow{4}{*}{$\begin{array}{l}\text { L4 } \\
\text { Obra } 3 \\
H=41,1 \mathrm{~m}\end{array}$} & \multirow{4}{*}{ 24/25/28/ago/17 } & $\begin{array}{l}\text { Montagem de fôrmas de pilares e vigas do } 12^{\circ} \\
\text { pavimento }\end{array}$ & 06 carpinteiros \\
\hline & & $\begin{array}{l}\text { Colocação das armações de aço nas fôrmas de } \\
\text { pilares e vigas da laje do } 12^{\circ} \text { pavimento }\end{array}$ & 02 armadores \\
\hline & & $\begin{array}{l}\text { Execução de alvenaria de elevação com blocos } \\
\text { de concreto }\end{array}$ & 02 pedreiros \\
\hline & & $\begin{array}{l}\text { Transporte de madeiramento e da estrutura de } \\
\text { andaimes de aço para escoramento de laje }\end{array}$ & 03 ajudantes (geral) \\
\hline \multirow{3}{*}{$\begin{array}{l}\mathrm{L} 5 \\
\text { Obra } 4 \\
\mathrm{H}=4,8 \mathrm{~m}\end{array}$} & \multirow{3}{*}{$13 / 14 / 15 /$ set/17 } & $\begin{array}{l}\text { Montagem de fôrmas de pilares e vigas do } 3^{\circ} \\
\text { pavimento }\end{array}$ & 03 carpinteiros \\
\hline & & $\begin{array}{l}\text { Colocação das armações de aço nas fôrmas de } \\
\text { pilares e vigas do } 3^{\circ} \text { pavimento }\end{array}$ & 01 armador \\
\hline & & $\begin{array}{l}\text { Transporte de madeiramento, de armações. } \\
\text { Auxílio nas instalações de fôrmas de madeira e } \\
\text { encaixe das armaçôes de aço nas fôrmas }\end{array}$ & 03 ajudantes (geral) \\
\hline \multirow{3}{*}{$\begin{array}{l}\text { L6 } \\
\text { Obra } 4 \\
\mathrm{H}=9,6 \mathrm{~m}\end{array}$} & \multirow{3}{*}{ 16/17/18/out/17 } & Montagem das fôrmas de vigas da cobertura & 02 carpinteiros \\
\hline & & $\begin{array}{l}\text { Colocação das armações de aço nas fôrmas de } \\
\text { vigas da cobertura }\end{array}$ & $\begin{array}{l}01 \text { armador (mesmo } \\
\text { que em setembro) }\end{array}$ \\
\hline & & $\begin{array}{l}\text { Transporte de madeiramento, de armações e de } \\
\text { blocos cerâmicos } \\
\text { Limpeza da laje e retirada de entulhos }\end{array}$ & $\begin{array}{l}01 \text { ajudante (geral) } \\
\text { (mesmo que em } \\
\text { setembro) }\end{array}$ \\
\hline $\begin{array}{l}\mathrm{L} 7 \\
\text { Obra } 5 \\
\mathrm{H}=12,8 \mathrm{~m} \\
\end{array}$ & 24/25/nov/17 & $(1)$ & $(1)$ \\
\hline \multirow{3}{*}{$\begin{array}{l}\text { L8 } \\
\text { Obra } 6 \\
\mathrm{H}=9,5 \mathrm{~m}\end{array}$} & \multirow{3}{*}{ 05/dez/17 } & $\begin{array}{l}\text { Montagem das fôrmas de pilares e vigas da laje } \\
\text { do } 6^{\circ} \text { pavimento }\end{array}$ & 02 carpinteiros \\
\hline & & $\begin{array}{l}\text { Colocação das armações de aço nas fôrmas dos } \\
\text { pilares e vigas da laje do } 6^{\circ} \text { pavimento }\end{array}$ & 02 armadores \\
\hline & & $\begin{array}{l}\text { Transporte de madeiramento, de armações. } \\
\text { Auxílio na montagem das fôrmas de madeira e } \\
\text { encaixe das armações de aço nas fôrmas }\end{array}$ & 01 ajudante (geral) \\
\hline
\end{tabular}


Quadro 3 - Atividades registradas e operários observados por laje, por subperíodo de medição (continuação)

\begin{tabular}{|c|c|c|c|}
\hline \multirow{3}{*}{$\begin{array}{l}\text { L9 } \\
\text { Obra } 6 \\
\mathrm{H}=12,6 \mathrm{~m}\end{array}$} & \multirow{3}{*}{ 11/dez/17 } & $\begin{array}{l}\text { Montagem das fôrmas de pilares e vigas da laje do } 7^{\circ} \\
\text { pavimento }\end{array}$ & 02 carpinteiros \\
\hline & & $\begin{array}{l}\text { Colocação das armações de aço nas fôrmas de pilares } \\
\text { e vigas da laje do } 7^{\circ} \text { pavimento }\end{array}$ & $\begin{array}{l}02 \text { armadores } \\
\text { (mesmos que no dia } \\
05 / 12 \text { ) }\end{array}$ \\
\hline & & $\begin{array}{l}\text { Transporte de madeiramento, de armações. Auxílio na } \\
\text { montagem de fôrmas de madeira e encaixe das } \\
\text { armações de aço nas fôrmas }\end{array}$ & $\begin{array}{l}01 \text { ajudante (geral) } \\
\text { (mesmo que no dia } \\
05 / 12 \text { ) }\end{array}$ \\
\hline \multirow{3}{*}{$\begin{array}{l}\mathrm{L} 10 \\
\text { Obra } 6 \\
\mathrm{H}=15,6 \mathrm{~m}\end{array}$} & \multirow{3}{*}{ 20/dez/17 } & $\begin{array}{l}\text { Montagem das fôrmas de pilares e vigas da laje do } 8^{\circ} \\
\text { pavimento }\end{array}$ & 02 carpinteiros \\
\hline & & $\begin{array}{l}\text { Colocação das armações de aço nas fôrmas de pilares } \\
\text { e vigas da laje do } 8^{\circ} \text { pavimento }\end{array}$ & $\begin{array}{l}\text { 02 armadores } \\
\text { (mesmos que no dia } \\
11 / 12 \text { ) }\end{array}$ \\
\hline & & $\begin{array}{l}\text { Transporte de madeiramento, de armações. Auxílio na } \\
\text { montagem das fôrmas de madeira e encaixe das } \\
\text { armações de aço nas fôrmas }\end{array}$ & 01 ajudante (geral) \\
\hline $\begin{array}{l}\text { L11 } \\
\text { Obra } 4 \\
\mathrm{H}=9,6 \mathrm{~m}\end{array}$ & 26/jan/18 & $\begin{array}{l}\text { Execução de alvenaria de elevação com blocos de } \\
\text { concreto para platibanda da cobertura }\end{array}$ & 02 pedreiros \\
\hline \multirow{3}{*}{$\begin{array}{l}\mathrm{L} 12 \\
\text { Obra } 6 \\
\mathrm{H}=31,1 \mathrm{~m}\end{array}$} & \multirow{3}{*}{ 27/jan/18 } & $\begin{array}{l}\text { Montagem das fôrmas de pilares e vigas da laje do } 10^{\circ} \\
\text { pavimento }\end{array}$ & 02 carpinteiros \\
\hline & & $\begin{array}{l}\text { Colocação das armações de aço nas fôrmas de pilares } \\
\text { e vigas da laje do } 10^{\circ} \text { pavimento }\end{array}$ & 02 armadores \\
\hline & & $\begin{array}{l}\text { Transporte de madeiramento, de armações. Auxílio na } \\
\text { montagem e encaixe das armações de aço nas fôrmas }\end{array}$ & 01 ajudante (geral) \\
\hline $\begin{array}{l}\text { L13 } \\
\text { Obra } 4 \\
\mathrm{H}=9,6 \mathrm{~m}\end{array}$ & 31/jan/18 & $\begin{array}{l}\text { Execução de alvenaria de elevação com blocos de } \\
\text { concreto para platibanda da cobertura }\end{array}$ & 02 pedreiros \\
\hline \multirow{3}{*}{$\begin{array}{l}\mathrm{L} 14 \\
\text { Obra } 6 \\
\mathrm{H}=34,0 \mathrm{~m}\end{array}$} & \multirow{3}{*}{ 02/fev/18 } & $\begin{array}{l}\text { Montagem das fôrmas de pilares e vigas da laje do } 14^{\circ} \\
\text { pavimento }\end{array}$ & 02 carpinteiros \\
\hline & & $\begin{array}{l}\text { Colocação das armações de aço nas fôrmas de pilares } \\
\text { e vigas da laje do } 14^{\circ} \text { pavimento }\end{array}$ & $\begin{array}{l}\text { 02 armadores } \\
\text { (mesmos que no dia } \\
27 / 01 \text { ) }\end{array}$ \\
\hline & & $\begin{array}{l}\text { Transporte de madeiramento, de armações. Auxílio na } \\
\text { montagem das fôrmas de madeira e encaixe das } \\
\text { armações de aço nas fôrmas }\end{array}$ & $\begin{array}{l}01 \text { ajudante (geral) } \\
\text { (mesmo que no dia } \\
\text { 27/01) }\end{array}$ \\
\hline \multirow{3}{*}{$\begin{array}{l}\mathrm{L} 15 \\
\text { Obra } 6 \\
\mathrm{H}=37,0 \mathrm{~m}\end{array}$} & \multirow{3}{*}{ 08/fev/18 } & $\begin{array}{l}\text { Montagem de fôrmas de pilares e vigas da laje do } 15^{\circ} \\
\text { pavimento }\end{array}$ & $\begin{array}{l}02 \text { carpinteiros (mesmos } \\
\text { que no dia } 02 / 02 \text { ) }\end{array}$ \\
\hline & & $\begin{array}{l}\text { Colocação das armações de aço nas fôrmas de pilares } \\
\text { e vigas da laje do } 15^{\circ} \text { pavimento }\end{array}$ & $\begin{array}{l}02 \text { armadores } \\
\text { (mesmos que no dia } \\
02 / 02 \text { ) }\end{array}$ \\
\hline & & $\begin{array}{l}\text { Transporte de madeiramento, de armações. Auxílio na } \\
\text { montagem das fôrmas de madeira e encaixe das } \\
\text { armações de aço nas fôrmas }\end{array}$ & 01 ajudante (geral) \\
\hline $\begin{array}{l}\text { L16 } \\
\text { Obra } 1 \\
\mathrm{H}=7,2 \mathrm{~m}\end{array}$ & 24/fev/18 & (1) & (1) \\
\hline \multirow{3}{*}{$\begin{array}{l}\mathrm{L} 17 \\
\text { Obra } 6 \\
\mathrm{H}=46,4 \mathrm{~m}\end{array}$} & \multirow{3}{*}{ 19/mar/18 } & $\begin{array}{l}\text { Montagem das fôrmas de pilares e vigas da laje da } \\
\text { cobertura }\end{array}$ & $\begin{array}{l}02 \text { carpinteiros (mesmos } \\
\text { que no dia } 08 / 02 \text { ) }\end{array}$ \\
\hline & & $\begin{array}{l}\text { Colocação das armações de aço nas fôrmas de pilares } \\
\text { e vigas da laje da cobertura }\end{array}$ & $\begin{array}{l}01 \text { armador (mesmo que } \\
\text { no dia } 08 / 02 \text { ) }\end{array}$ \\
\hline & & $\begin{array}{l}\text { Transporte de madeiramento, de armações. Auxílio } \\
\text { nas instalações de fôrmas de madeira e encaixe das } \\
\text { armações de aço nas fôrmas }\end{array}$ & $\begin{array}{l}01 \text { ajudante (geral) } \\
\text { (mesmo que no dia } \\
08 / 02 \text { ) }\end{array}$ \\
\hline
\end{tabular}

Nota: Legenda:

(H) altura da laje em relação ao nível do pavimento térreo da edificação; e

(1) não houve observação simultânea das atividades. 
Figura 1 - Monitor de exposição ao calor QuesTemp36 ${ }^{\mathrm{m}}$ : em (a) posicionado em laje; em (b) detalhe do monitor

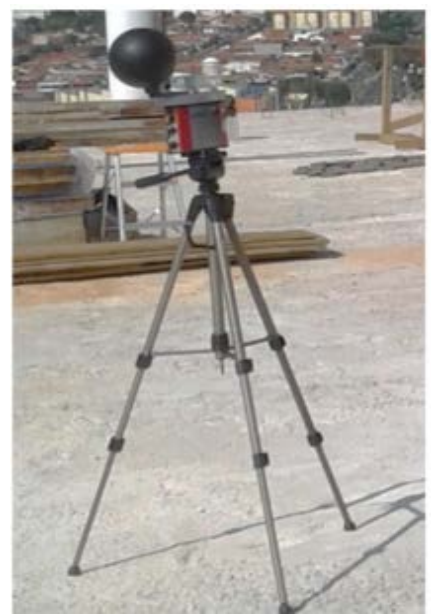

(a)

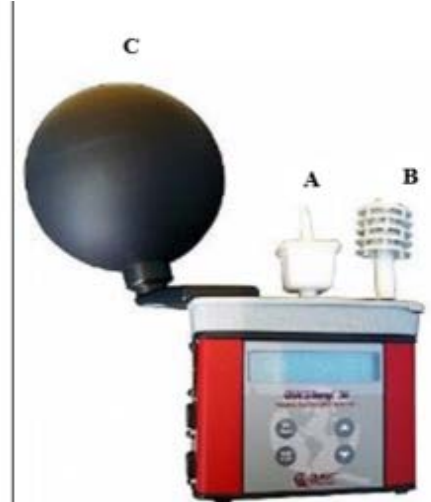

(b)

Fonte: (b) 3M-Central Brasil Instrumentos (2019).

Nota: (b) A é o termômetro de bulbo úmido natural; B é o termômetro de bulbo seco; e C é o termômetro de globo.

\section{Resultados e discussões}

Os resultados das taxas de calor metabólico para carpinteiros, armadores, pedreiros e ajudantes, calculados pelo método especificado na norma ISO 8996 (INTERNATIONAL..., 2004) e classificações segundo a ACGIH (AMERICAN..., 2010), na legislação brasileira, através da NR-15 (BRASIL, 1978) e na própria ISO 8996 (INTERNATIONAL..., 2004), são apresentados na Tabela 1.

Na montagem de fôrma em madeira para a estrutura de pilares e vigas (dimensões aproximadas de 25x35x345 cm) observou-se uma série de 14 tarefas mais relevantes executadas pelos carpinteiros (Quadro 3), perfazendo um ciclo de trabalho de duração de aproximadamente 172 min. Assim, obteve-se a taxa metabólica média (M) de $217 \mathrm{kcal} / \mathrm{h}$.

Como indicado na Tabela 1, as três normas ACGIH (AMERICAN..., 2010), ISO 8996 (INTERNATIONAL..., 2004) e NR-15 (BRASIL, 2018a) classificam essa atividade como moderada. Para carpinteiros, a norma ISO 8996 (INTERNATIONAL..., 2004) apresenta valores médios de taxa metabólica de 110-175 W/m² (200-319 W).

Constatou-se na atividade de montagem da armação dos vergalhões de aço dos pilares e vigas uma série de seis tarefas mais relevantes, executadas pelos armadores, perfazendo um ciclo de trabalho com duração de 125 min, o que resultou em uma taxa metabólica média de $236 \mathrm{kcal} / \mathrm{h}$, ou $279 \mathrm{~W}$.

Os ajudantes, por sua vez, exerceram as atividades de auxílio na montagem das fôrmas e armações e na execução de alvenaria, além de transporte de materiais, limpeza e retirada de entulhos das lajes a céu aberto. O período do ciclo de trabalho foi de difícil determinação, pois variava muito, conforme a ordem das tarefas que são realizadas. No entanto, foram muitos os deslocamentos, subindo e descendo escadas para transporte manual de materiais, limpeza da obra e retirada de entulhos (Quadro 3). Assim, neste estudo foi considerada apenas uma série de seis tarefas, as mais frequentes, para cálculo da média das taxas metabólicas. A média dos ajudantes dos carpinteiros, armadores e pedreiros atingiu $390 \mathrm{kcal} / \mathrm{h}$, razão pela qual essa atividade foi classificada como “alta” segundo a norma ISO 8996 (INTERNATIONAL..., 2004) e “pesada” segundo a NR15 (BRASIL, 2018a).

Os pedreiros executaram tarefas de alvenaria de blocos estruturais para construção de platibandas nas lajes de cobertura, com ciclos de trabalho longos, o que resultou em um metabolismo médio de $230 \mathrm{kcal} / \mathrm{h}$, enquadrando em atividade moderada. Para pedreiros, a norma ISO 8996 (INTERNATIONAL, 2004) apresenta valores médios de 110-160 W/m² (200- 291W).

Os dados de efetiva exposição ao calor expressos por 297 valores médios horários de IBUTG, em um período de 1 ano (10/03/2017 a 19/03/2018) estão mostrados na Tabela 2. As medições cobriram um período diário de 9 h, sendo 1 hora para as refeições, e resultaram em altos valores de exposição, principalmente após o meiodia, tendo atingido o maior valor médio às $14 \mathrm{~h}$. As condições térmicas de maior risco, como se poderia esperar, 
ocorreram entre outubro e março, atingindo valores mínimo, médio e máximo nesse período de 25,4 ${ }^{\circ} \mathrm{C}, 29,4$ ${ }^{\circ} \mathrm{C}$ e $32,2{ }^{\circ} \mathrm{C}$ respectivamente. Dessa forma, conclui-se que as empresas deveriam dar maior atenção à implantação de medidas de controle de exposição ao calor no período vespertino e nas estações mais quentes do ano.

Tabela 1 - Taxas de calor metabólico por função

\begin{tabular}{l|c|c|l|l|l}
\hline \multirow{2}{*}{ Função } & \multicolumn{2}{|c|}{ Taxa metabólica média ${ }^{(\mathbf{a})}$} & \multicolumn{3}{c}{ Categoria de taxa metabólica - Trabalho } \\
\cline { 2 - 6 } & W & kcal/h$^{(\mathbf{b})}$ & ISO 8996 (2004) & ACGIH (2010) & NR-15 (BRASIL, 2018a) \\
\hline Carpinteiro & 252 & 217 & Moderada & Moderado & Moderado \\
Armador & 279 & 236 & Moderada & Moderado & Moderado \\
Pedreiro & 267 & 230 & Moderada & Moderado & Moderado \\
Ajudante & 454 & 390 & Alta & Pesado & Pesado \\
\hline
\end{tabular}

Notas: (a) taxa metabólica para o homem padrão (área superficial igual a 1,8 $\mathrm{m}^{2}$ e peso de $70 \mathrm{~kg}$ ); e (b) conversão de unidades para o homem padrão $1 \mathrm{kcal} / \mathrm{h}=0,859845 \times[\mathrm{W}]$.

Tabela 2 - IBUTG médio e mediano, por hora e por dia de medição

\begin{tabular}{|c|c|c|c|c|c|c|c|c|c|c|}
\hline \multirow{2}{*}{ Laje } & \multirow{2}{*}{ Data } & \multicolumn{9}{|c|}{ IBUTG $\left({ }^{\circ} \mathrm{C}\right)$} \\
\hline & & $8 \mathrm{~h}$ & $9 \mathrm{~h}$ & $10 \mathrm{~h}$ & 11h & $12 \mathrm{~h}$ & 13h & $14 \mathrm{~h}$ & 15h & $16 \mathrm{~h}$ \\
\hline \multirow{6}{*}{ L1 } & $10 / 03 / 17$ & 24,2 & 27,0 & 28,0 & 29,3 & 30,6 & 31,0 & 30,7 & 31,8 & 30,7 \\
\hline & $11 / 03 / 17$ & 24,6 & 27,5 & 28,0 & 29,1 & 30,3 & 30,8 & 32,2 & 31,5 & 28,1 \\
\hline & $13 / 03 / 17$ & 24,8 & 27,8 & 28,4 & 28,0 & 28,7 & 29,7 & 30,3 & 27,8 & 26,9 \\
\hline & $16 / 03 / 17$ & 24,9 & 25,6 & 26,3 & 27,9 & 29,0 & 29,3 & 29,4 & 29,8 & 29,4 \\
\hline & $17 / 03 / 17$ & 24,5 & 27,2 & 27,5 & 28,0 & 29,0 & 29,7 & 30,3 & 30,1 & 30,2 \\
\hline & $18 / 03 / 17$ & 24,0 & 25,1 & 24,1 & 24,8 & 24,6 & 24,4 & 25,9 & 25,3 & 23,1 \\
\hline \multirow{3}{*}{ L2 } & $22 / 03 / 17$ & 20,4 & 24,1 & 25,9 & 26,7 & 27,6 & 27,3 & 29,1 & 27,4 & 27,0 \\
\hline & $23 / 03 / 17$ & 18,6 & 21,1 & 24,4 & 25,7 & 27,4 & 26,9 & 27,9 & 28,0 & 28,1 \\
\hline & $24 / 03 / 17$ & 21,3 & 23,4 & 24,6 & 26,7 & 27,4 & 28,5 & 28,9 & 30,6 & 29,2 \\
\hline \multirow{3}{*}{ L3 } & $02 / 05 / 17$ & 17,7 & 18,2 & 19,2 & 20,7 & 23,0 & 25,0 & 26,0 & 26,4 & 25,6 \\
\hline & $03 / 05 / 17$ & 17,9 & 20,4 & 23,3 & 25,2 & 25,8 & 26,5 & 26,1 & 26,2 & 26,2 \\
\hline & $04 / 05 / 17$ & 17,7 & 20,2 & 22,9 & 24,1 & 24,8 & 24,9 & 25,2 & 24,6 & 24,8 \\
\hline \multirow{3}{*}{ L4 } & $24 / 08 / 17$ & 18,9 & 20,3 & 21,4 & 23,0 & 22,5 & 21,9 & 22,1 & 21,6 & 21,6 \\
\hline & $25 / 08 / 17$ & 18,0 & 18,2 & 19,9 & 23,1 & 25,2 & 25,5 & 26,6 & 26,4 & 26,0 \\
\hline & $28 / 08 / 17$ & 18,1 & 19,6 & 20,9 & 23,4 & 25,4 & 26,4 & 26,6 & 25,9 & 25,6 \\
\hline \multirow{3}{*}{ L5 } & $13 / 09 / 17$ & 22,1 & 22,2 & 23,7 & 24,5 & 25,3 & 26,7 & 27,0 & 25,1 & 25,8 \\
\hline & $14 / 09 / 17$ & 21,8 & 21,8 & 23,2 & 24,3 & 25,4 & 26,1 & 27,0 & 26,4 & 26,2 \\
\hline & $15 / 09 / 17$ & 24,0 & 24,2 & 24,7 & 26,1 & 27,4 & 28,1 & 26,2 & 27,0 & 26,9 \\
\hline \multirow{3}{*}{ L6 } & $17 / 10 / 17$ & 23,7 & 23,8 & 25,8 & 26,4 & 26,8 & 28,0 & 25,6 & 27,5 & 26,3 \\
\hline & $18 / 10 / 17$ & 24,8 & 24,8 & 26,1 & 26,9 & 27,1 & 28,0 & 29,4 & 28,9 & 26,6 \\
\hline & $19 / 10 / 17$ & 23,2 & 23,3 & 24,5 & 25,4 & 25,8 & 26,8 & 28,1 & 27,6 & 28,2 \\
\hline \multirow{2}{*}{ L7 } & $24 / 11 / 17$ & 23,1 & 23,8 & 26,1 & 27,9 & 28,4 & 28,2 & 27,6 & 27,9 & 28,1 \\
\hline & $25 / 11 / 17$ & 24,8 & 25,4 & 26,2 & 26,6 & 27,0 & 27,5 & 27,8 & 26,9 & 27,7 \\
\hline L8 & $05 / 12 / 17$ & 24,9 & 27,5 & 29,2 & 29,5 & 29,9 & 31,0 & 31,3 & 30,7 & 30,0 \\
\hline L9 & $11 / 12 / 17$ & 24,9 & 26,3 & 29,4 & 29,2 & 29,3 & 28,2 & 28,5 & 28,4 & 29,4 \\
\hline L10 & $20 / 12 / 17$ & 24,2 & 25,3 & 26,9 & 28,1 & 28,2 & 29,1 & 29,0 & 30,1 & 26,9 \\
\hline L11 & $26 / 01 / 18$ & 24,2 & 24,2 & 25,2 & 27,6 & 28,4 & 27,4 & 28,5 & 28,8 & 23,9 \\
\hline L12 & $27 / 01 / 18$ & 24,4 & 24,6 & 24,6 & 25,6 & 26,6 & 28,7 & 29,1 & 25,8 & 24,0 \\
\hline L13 & $31 / 01 / 18$ & 23,0 & 23,1 & 23,9 & 25,1 & 26,2 & 26,4 & 26,5 & 24,9 & 23,9 \\
\hline L14 & $02 / 02 / 18$ & 23,5 & 23,5 & 24,3 & 27,2 & 29,0 & 28,8 & 27,5 & 26,9 & 25,1 \\
\hline L15 & $08 / 02 / 18$ & 24,7 & 24,9 & 25,8 & 27,3 & 28,3 & 29,0 & 28,6 & 30,4 & 29,8 \\
\hline L16 & $24 / 02 / 18$ & 24,9 & 26,2 & 26,6 & 27,9 & 28,7 & 29,8 & 28,5 & 28,5 & 26,4 \\
\hline L17 & $19 / 03 / 18$ & 24,6 & 24,6 & 26,0 & 27,6 & 28,9 & 28,9 & 31,8 & 29,2 & 30,6 \\
\hline \multicolumn{2}{|c|}{ Média } & 22,6 & 23,8 & 25,1 & 26,3 & 27,2 & 27,7 & 28,0 & 27,7 & 26,9 \\
\hline \multicolumn{2}{|c|}{ Mediana } & 24,0 & 24,2 & 25,2 & 26,7 & 27,4 & 28,0 & 28,1 & 27,6 & 26,9 \\
\hline
\end{tabular}

Nota: dados das $264 \mathrm{~h}$ efetivas de exposição e das $33 \mathrm{~h}$ de almoço contabilizadas às $12 \mathrm{~h}$. 
Tendo em vista que as atividades de carpinteiros, armadores e pedreiros são classificadas como moderadas (180 Kcal/h a $300 \mathrm{Kcal} / \mathrm{h}$ ), de acordo com o Anexo 3 da NR-15 (BRASIL, 2018a) e que o valor mediano das médias horárias de IBUTG a partir das $11 \mathrm{~h}\left(26,7^{\circ} \mathrm{C}\right)$ é igual ou maior que o respectivo limite de tolerância $\left(26,7^{\circ} \mathrm{C}\right)$, assim, em pelo menos $50 \%$ da jornada de trabalho, entre $12 \mathrm{~h}$ e $17 \mathrm{~h}$, haveria necessidade de pausas de $15 \mathrm{~min}, 30 \mathrm{~min}$ ou $45 \mathrm{~min}$ por hora de trabalho. Da mesma forma, como o valor mediano de IBUTG atingiu $25,2^{\circ} \mathrm{C}$ e foi maior que o limite de tolerância para atividades pesadas $\left(25,0^{\circ} \mathrm{C}\right)$ a partir das $10 \mathrm{~h}$, então haveria a necessidade das pausas em mais de $67 \%$ (6/9 h de exposição) do tempo da jornada de trabalho.

A Tabela 3 expressa, por dia avaliado, a frequência relativa das ocorrências de pausas para descanso térmico (em \%), por laje e respectivo subperíodo (de um a até seis dias de medição, conforme a Tabela 1) de cada regime de trabalho/descanso (RTD) necessário para a preservação da saúde dos trabalhadores nos locais avaliados. A ocorrência do RTD para trabalhos intermitentes (45/15 min, 30/30 min, 15/45 min, e trabalho não permitido) se deu quando os limites de tolerância (LT) foram ultrapassados em relação à atividade do tipo moderada.

Para a atividade moderada, observa-se que no período avaliado houve apenas três subperíodos nos quais o trabalho poderia ocorrer continuamente durante toda a jornada (100\%), isto é, sem pausas para recuperação térmica, definida como a volta da temperatura corporal à condição de normalidade, ou seja, aproximadamente $37^{\circ} \mathrm{C}$. Em média, 54\% das ocorrências (horas) apresentaram condições de exposição em que o IBUTG não atingiu o limite mínimo de tolerância para atividade moderada, de forma a permitir o trabalho contínuo. Nos outros 14 subperíodos haveria necessidade de pausas, em média 16\% no regime de 45/15 min, 20\% no regime 30/30 min, e 8\% no regime 15/45 min.

O trabalho não permitido (sem que medidas especiais de proteção fossem tomadas) ocorreu apenas em março/2017 (6\%), dezembro/2017 (13\%) e março/2018 (13\%), o que representa uma média de 2\% no período avaliado. Observa-se que esses resultados apontam para a necessidade de investimentos em programas de controle de exposição ao calor como o apontado pela instituição canadense OHSCO (OCCUPATIONAL..., 2007), já que o impacto das pausas sobre a hora trabalhada e o risco à saúde dos trabalhadores são notórios.

Tabela 3 - Frequência relativa da ocorrência de pausas durante a jornada de trabalho em atividade moderada para as 264 h de medição

\begin{tabular}{|c|c|c|c|c|c|c|}
\hline \multirow{4}{*}{ Laje } & \multicolumn{6}{|c|}{ Limites de tolerância (LT) } \\
\hline & \multirow{3}{*}{ Subperíodos $\downarrow$} & \multicolumn{5}{|c|}{$\begin{array}{l}\text { RTD para atividade de carpinteiros, armadores e pedreiros conforme o } \\
\text { Anexo } 3 \text { da NR-15 (BRASIL, 2018a) }\end{array}$} \\
\hline & & Contínuo & $45 / 15 \mathrm{~min}$ & $30 / 30 \mathrm{~min}$ & $15 / 45 \mathrm{~min}$ & Não permitido \\
\hline & & $<26,7^{\circ} \mathrm{C}$ & $26,8-28,0^{\circ} \mathrm{C}$ & $28,1-29,4^{\circ} \mathrm{C}$ & $29,5-31,1^{\circ} \mathrm{C}$ & $>31,1^{\circ} \mathrm{C}$ \\
\hline 1 & $\operatorname{mar} / 17^{(1)}$ & $31 \%$ & $25 \%$ & $15 \%$ & $23 \%$ & $6 \%$ \\
\hline 2 & $\operatorname{mar} / 17^{(2)}$ & $50 \%$ & $25 \%$ & $21 \%$ & $4 \%$ & $0 \%$ \\
\hline 3 & maio/17 & $100 \%$ & $0 \%$ & $0 \%$ & $0 \%$ & $0 \%$ \\
\hline 4 & ago/17 & $100 \%$ & $0 \%$ & $0 \%$ & $0 \%$ & $0 \%$ \\
\hline 5 & set/17 & $79 \%$ & $17 \%$ & $4 \%$ & $0 \%$ & $0 \%$ \\
\hline 6 & out/17 & $58 \%$ & $25 \%$ & $17 \%$ & $0 \%$ & $0 \%$ \\
\hline 7 & nov/17 & $44 \%$ & $44 \%$ & $12 \%$ & $0 \%$ & $0 \%$ \\
\hline 8 & 05/dez/17 & $13 \%$ & $12 \%$ & $12 \%$ & $50 \%$ & $13 \%$ \\
\hline 9 & 11/dez/17 & $25 \%$ & $0 \%$ & $75 \%$ & $0 \%$ & $0 \%$ \\
\hline 10 & 20/dez/17 & $25 \%$ & $25 \%$ & $38 \%$ & $12 \%$ & $0 \%$ \\
\hline 11 & 26/jan/18 & $50 \%$ & $25 \%$ & $25 \%$ & $0 \%$ & $0 \%$ \\
\hline 12 & 27/jan/18 & $75 \%$ & $0 \%$ & $25 \%$ & $0 \%$ & $0 \%$ \\
\hline 13 & 31/jan/18 & $100 \%$ & $0 \%$ & $0 \%$ & $0 \%$ & $0 \%$ \\
\hline 14 & 02/fev/18 & $50 \%$ & $38 \%$ & $12 \%$ & $0 \%$ & $0 \%$ \\
\hline 15 & 08/fev/18 & $38 \%$ & $12 \%$ & $25 \%$ & $25 \%$ & $0 \%$ \\
\hline 16 & 24/fev/18 & $50 \%$ & $12 \%$ & $25 \%$ & $13 \%$ & $0 \%$ \\
\hline 17 & 19/mar/18 & $38 \%$ & $12 \%$ & $25 \%$ & $12 \%$ & $13 \%$ \\
\hline & Média & $54 \%$ & $16 \%$ & $20 \%$ & $8 \%$ & $2 \%$ \\
\hline
\end{tabular}

Nota: Subperíodo (1): corresponde às medições entre 10 e 18 de março de 2017 na Laje 1. Subperíodo (2): corresponde às medições entre 22 e 24 de março de 2017 na Laje 2. 
A Tabela 4 apresenta, conforme a NR-15 (BRASIL, 2018a), a frequência relativa da ocorrência de pausas durante a jornada de trabalho em atividades pesadas, como a dos ajudantes. Como no caso das outras categorias, essas pausas deveriam ter ocorrido caso a empresa observasse a norma brasileira. Como visto na Tabela 1, esses trabalhadores apresentaram uma taxa de calor metabólico maior que a das outras categorias profissionais estudadas (390 kcal/h). Por essa razão, o limite de tolerância para esse tipo de atividade é menor que o das outras, o que indica que para a preservação da saúde dos ajudantes são necessárias mais pausas. Observa-se que, em média, apenas em 33\% dos subperíodos poderiam ser exercidos sem aplicação do RTD, enquanto em 10\%, 26\% e 24\% deles as empresas deveriam respeitar as pausas de recuperação térmica de 15 min, 30 min e 45 min por hora de trabalho respectivamente.

Os subperíodos em que o trabalho deveria ter sido proibido sem as devidas cautelas especiais de segurança foram registrados em março/2017 (23\%), 05/dez/2017 (38\%), 20/dez/2017 e 08/fev/2018 (13\%) e 19/março/2018 (25\%).

Como se pode observar, o impacto desses resultados sobre a hora trabalhada e, possivelmente, sobre a produção dos ajudantes é bem maior do que nas atividades dos carpinteiros, armadores e pedreiros, já que maiores investimentos seriam necessários para preservação da saúde e para remunerar as horas não trabalhadas. Ressalta-se que os períodos de descanso são considerados tempo de serviço para todos os efeitos legais da NR-15 (BRASIL, 2018a).

A Figura 2 mostra, de cima para baixo, o cálculo da soma das horas efetivamente trabalhadas em RTD, o total das horas de pausas necessárias para recuperação térmica, o número de horas nas quais o trabalho deveria ser proibido sem que medidas de controle especial fossem adotadas pela empresa conforme a NR-15 (BRASIL, 2018a), já que as condições térmicas apresentavam alto risco de sobrecarga térmica, e o número de horas de pausas em regime de 15/45 min, 30/30 min e 45/15 min. A Figura 2 apresenta ainda a soma das horas em que o trabalho poderia ocorrer continuamente para atividades moderadas e pesadas.

Tabela 4 - Frequência relativa da ocorrência de pausas durante a jornada de trabalho em atividade pesada

\begin{tabular}{|c|c|c|c|c|c|c|}
\hline \multirow{4}{*}{ Laje } & \multirow{4}{*}{ Subperíodos } & \multicolumn{5}{|c|}{ Limites de tolerância (LT) } \\
\hline & & \multicolumn{5}{|c|}{$\begin{array}{l}\text { RTD para atividade de ajudantes conforme o Anexo } 3 \text { da NR-15 } \\
\text { (BRASIL, 2018a) }\end{array}$} \\
\hline & & Contínuo & $45 / 15 \mathrm{~min}$ & $30 / 30 \mathrm{~min}$ & $15 / 45 \mathrm{~min}$ & Não permitido \\
\hline & & $<25,0^{\circ} \mathrm{C}$ & $25,1-25,9^{\circ} \mathrm{C}$ & $26,0-27,9^{\circ} \mathrm{C}$ & $28,0-30,0^{\circ} \mathrm{C}$ & $>30^{\circ} \mathrm{C}$ \\
\hline 1 & mar/17 (1) & $21 \%$ & $8 \%$ & $19 \%$ & $29 \%$ & $23 \%$ \\
\hline 2 & mar/17 (2) & $33 \%$ & $9 \%$ & $29 \%$ & $25 \%$ & $4 \%$ \\
\hline 3 & maio/17 & $63 \%$ & $12 \%$ & $25 \%$ & $0 \%$ & $0 \%$ \\
\hline 4 & ago/17 & $67 \%$ & $12 \%$ & $21 \%$ & $0 \%$ & $0 \%$ \\
\hline 5 & set/17 & $46 \%$ & $8 \%$ & $42 \%$ & $4 \%$ & $0 \%$ \\
\hline 6 & out/17 & $29 \%$ & $13 \%$ & $33 \%$ & $25 \%$ & $0 \%$ \\
\hline 7 & nov/17 & $19 \%$ & $12 \%$ & $56 \%$ & $13 \%$ & $0 \%$ \\
\hline 8 & 05/dez/17 & $12 \%$ & $0 \%$ & $12 \%$ & $38 \%$ & $38 \%$ \\
\hline 9 & 11/dez/17 & $12 \%$ & $0 \%$ & $13 \%$ & $75 \%$ & $0 \%$ \\
\hline 10 & 20/dez/17 & $12 \%$ & $12 \%$ & $25 \%$ & $38 \%$ & $13 \%$ \\
\hline 11 & 26/jan/18 & $38 \%$ & $12 \%$ & $25 \%$ & $25 \%$ & $0 \%$ \\
\hline 12 & 27/jan/18 & $50 \%$ & $25 \%$ & $0 \%$ & $25 \%$ & $0 \%$ \\
\hline 13 & 31/jan/18 & $63 \%$ & $12 \%$ & $25 \%$ & $0 \%$ & $0 \%$ \\
\hline 14 & 02/fev/18 & $38 \%$ & $12 \%$ & $38 \%$ & $12 \%$ & $0 \%$ \\
\hline 15 & 08/fev/18 & $25 \%$ & $12 \%$ & $12 \%$ & $38 \%$ & $13 \%$ \\
\hline 16 & 24/fev/18 & $12 \%$ & $0 \%$ & $50 \%$ & $38 \%$ & $0 \%$ \\
\hline 17 & 19/mar/18 & $25 \%$ & $0 \%$ & $25 \%$ & $25 \%$ & $25 \%$ \\
\hline \multicolumn{2}{|r|}{ Média } & $33 \%$ & $10 \%$ & $26 \%$ & $24 \%$ & $7 \%$ \\
\hline
\end{tabular}

Nota: Subperíodo (1): corresponde as medições entre 10 e 18 de março de 2017 na Laje 1. Subperíodo (2): corresponde as medições entre 22 e 24 de março de 2017 na Laje 2. 
Figura 2 - Número de horas efetivamente trabalhadas e de pausas no RTD em atividade moderada e pesada em 264 h de medição

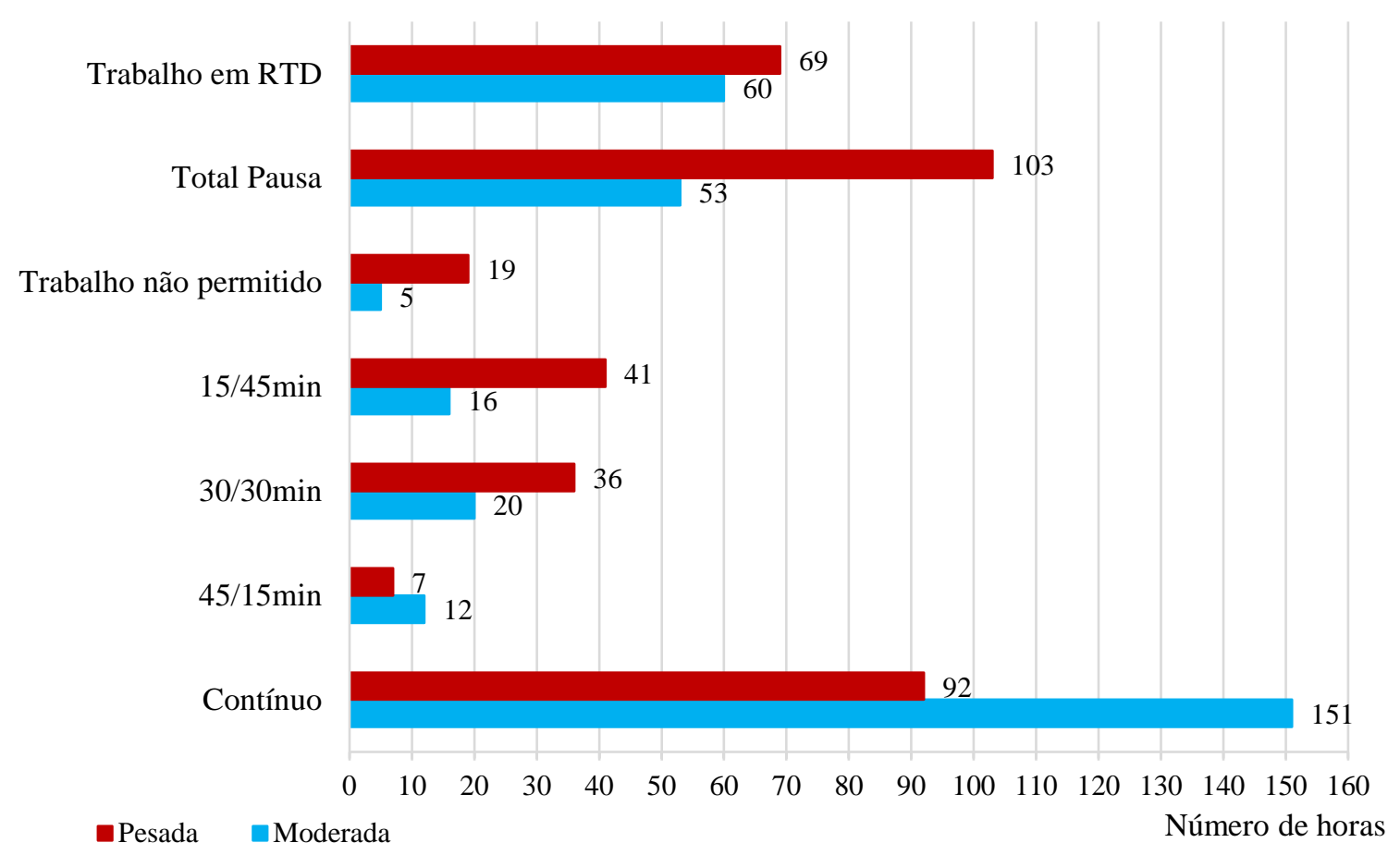

Observa-se que, para os trabalhadores que realizavam atividade pesada, ou seja, os ajudantes, do total de 264 (69+103+92) h de medição 92 h (35\%) correspondem ao regime de trabalho contínuo, isto é, horas completas de trabalho, sem pausas de repouso térmico, 41 h (16\%) correspondem ao trabalho intermitente em regime de 15/45 min, 36 h (14\%) correspondem ao regime 30/30 min; 7 h (3\%) ao regime de 45/15 min, e 19 h (7\%) correspondem ao tempo de trabalho não permitido, ou seja, $1 \mathrm{~h}$ completa de repouso, perfazendo um total de $103(19+41+36+7)$ h (39\%) de interrupções das atividades dos trabalhadores durante o período analisado (março de 2017 a março de 2018).

Em relação aos trabalhadores que realizam atividade moderada, a exposição é um pouco menor, mas ainda significativa. Do tempo total de coleta de dados, 53 h deveriam ser despendidas em recuperação térmica ou em paradas obrigatórias, perfazendo 20\% do total. Vê-se na Figura 2 que 16 h, 20 h e 12 h obrigatoriamente, segundo a NR-15 (BRASIL, 2018a), deveriam ser consumidas em repouso térmico em RTD de 15/45 min, 30/30 min e 45/15 min, enquanto em 5 h do período estudado deveria haver proibição do trabalho porque as condições térmicas ambientais ultrapassaram o limite de tolerância máximo estabelecido na norma.

Considerando que em ambientes quentes, para qualquer jornada laboral, a norma NR-15 (BRASIL, 2018a) estabelece que, sempre que o valor do IBUTG ultrapassar os limites de tolerância, deve-se aplicar pausas de repouso e que essas pausas se contabilizam por hora de trabalho em $15 \mathrm{~min}, 30 \mathrm{~min}$ ou $45 \mathrm{~min}$ por hora ou mesmo a hora completa, conforme o valor do IBUTG. Os resultados mostram que haveria grande impacto das paralisações das atividades sobre a jornada de trabalho e um possível impacto significativo sobre a produção anual dos profissionais em estudo caso as pausas normalizadas por lei fossem realmente aplicadas pelas empresas. Por outro lado, quando não são aplicadas, têm um impacto sobre a saúde dos trabalhadores, causando as doenças do calor, em especial câimbras, exaustão térmica e insolação. Nesse cenário, além das paralisações necessárias, a adoção de medidas de controle de riscos (como o monitoramente diário de exposiçao ao calor), assim como o uso de roupas com isolamento térmico recomendado pela ISO 9920 (INTERNATIONAL..., 2009), e de protetores solares combinados com uma hidratação adequada, pode ser suficiente para prevenção de câimbras, exaustão térmica, insolação e outras doenças do calor.

Embora as empresas avaliadas não apliquem as pausas recomendadas por lei, elas oferecem vestimentas adequadas, equipamentos de proteção indiviual, protetores solares e hidratação adequada. 
Os resultados mostraram que para carpinteiros, armadores e pedreiros, em 264 h de exposição, 53 h (20\%) deveriam ser despendidas em pausas ou interrupção total do trabalho. Para os ajudantes, o impacto seria ainda ainda maior, $103 \mathrm{~h}$ (39\%).

Considerando que a coleta de dados foi realizada de março de 2017 a março de 2018 e cobriu subperíodos em todas as estações do ano, em dias aleatórios, nos quais houve autorização das construtoras para a realização dos trabalhos, estima-se que em 1 ano de 2.112 h de trabalho (44 h/semana, 4 semanas/mês, 12 meses/ano) deveriam ocorrer $824 \mathrm{~h}$ de paralisações de ajudantes e $422 \mathrm{~h}$ de carpinteiros, armadores e pedreiros em trabalho sobre lajes na construção de estruturas de edifícios.

Por fim, conclui-se que, embora as pausas necessárias sejam uma necessidade legal e fisiológica para evitar as doenças oriundas da exposição laboral ao calor, elas podem ter impacto considerável sobre o número de horas trabalhadas, podendo ter reflexos financeiros sobre as empresas. No entanto, esses reflexos poderiam ser conpensados com melhor ritmo de trabalho, menor número de afastamentos e diminuição do número de processos judiciais e indenizações. É importante destinar investimentos relativos para o monitoramento diário de exposição, uso de roupas mais confortáveis, aplicação de protetores solares para pele e hidratação adequada, entre outras medidas de gerenciamento de controle da exposição, visando à prevenção das doenças relacionadas ao calor, o que resultará em menores despesas com absenteísmo, substituição de trabalhadores adoecidos e prejuízos relacionados com a fiscalização de saúde e segurança do trabalho, bem como idenizações legais.

\section{Considerações finais}

Os resultados demonstraram que carpinteiros, armadores, pedreiros e ajudantes ficaram expostos a condições ambientais que resultaram em valores de IBUTG frequentemente acima dos limites de tolerâncias estabelecidos pela legislação brasileira. Essas condições demonstraram que os trabalhadores poderiam sofrer doenças relacionadas ao calor, como câimbras, prostração térmica, exaustão e insolação, esta última com potencial de lesões permanentes e de morte.

Para evitar essas doenças, além de outras medidas, se fazem necessárias pausas a cada hora de trabalho, ou mesmo a interrupção das atividades sempre que a exposição ultrapasse os limites de tolerância estabelecidos pela NR-15 (BRASIL, 2018a). Nessas condições, a quantidade de pausas e suas durações no trabalho a céu aberto sobre lajes, se aplicadas, impactariam significantemente no ritmo de trabalho de cada operário, frequentemente exigindo $15 \mathrm{~min}, 30 \mathrm{~min}$ e 45 min de descanso para recuperação térmica do corpo em cada período de 1 hora de trabalho. Esse RTD, embora obrigatório, dificilmente tem sido adotado pelas empresas, razão pela qual se têm aplicado multas pelos órgãos responsáveis pela fiscalização do trabalho e indenizações cobradas em processos civis e trabalhistas.

Os empresários da construção civil deveriam estar conscientes de que as ações de prevenção dessas doenças e dos riscos nas atividades exercidas a céu aberto na construção civil são importantes, pois são formas de valorizar e preservar a qualidade de vida do trabalhador, assim como de melhorar o desempenho na produção das empresas e de evitar prejuízos decorrentes de multas e indenizações.

\section{Referências}

3M. Central Brasil Instrumentos. Medidor de stress térmico Mod. QT36/6. Disponível em: http://www.centralbrasilinstrumentos.com.br/seguranca-do-trabalho/termometro-de-globo/medidor-destress-termico-mod--qt34-6. Acesso em: 28 fev. 2019.

AMERICAN CONFERENCE OF GOVERNAMENTAL INDUSTRIAL HYGIENISTS. TLV'S e BEI'S: limites de exposição ocupacional (TLV’s) para substâncias químicas e agentes físicos e índices biológicos de exposição. Cincinnati, 2010.

AMORIM, A. E. B. et al. Qualidade dos dados do Índice de Bulbo Úmido-Termômetro de Globo (IBUTG) coletados com instrumentos automáticos em ambiente externo. In: ENCONTRO NACIONAL DE TECNOLOGIA DO AMBIENTE CONSTRUÍDO, 17., Foz do Iguaçu, 2018. Anais [...] Porto Alegre: ANTAC, 2018.

BRASIL. Ministério do Trabalho. Portaria GM n 2.037, de 15 de dezembro de 1999, que altera a Norma Regulamentadora No 21 - Trabalho a Céu Aberto. Brasília, 1999. Disponível em: https://enit.trabalho.gov.br/portal/images/Arquivos_SST/SST_NR/NR-21.pdf. Acesso em: 24 jul. 2019. 
BRASIL. Ministério do Trabalho. Portaria MTb n. ${ }^{\circ}$ 871, de 6 de julho de 2017, que altera a Norma Regulamentadora No 9 - Programa de Prevenção de Riscos Ambientais - PPRA. Brasília, 2017b. Disponível em: https://enit.trabalho.gov.br/portal/images/Arquivos_SST/SST_NR/NR-09.pdf. Acesso em: 24 jul. 2019.

BRASIL. Ministério do Trabalho. Portaria MTb no 1.084, de 18 de dezembro de 2018, que altera a Norma Regulamentadora No 15 - Atividades e Operações Insalubres. Brasília, 2018a. Disponível em: https://enit.trabalho.gov.br/portal/images/Arquivos_SST/SST_NR/NR-15.pdf. Acesso em: 24 jul. 2019.

BRASIL. Ministério do Trabalho. Portaria MTb no 261, de 18 de abril de 2018, que altera a Norma Regulamentadora $N^{0} 18$ - Condições e Meio Ambiente de Trabalho na Indústria da Construção. Brasília, 2018b. Disponível em: https://enit.trabalho.gov.br/portal/images/Arquivos_SST/SST_NR/NR-18.pdf. Acesso em: 24 jul. 2019.

BRASIL. Ministério do Trabalho. Portaria MTb nº 877, de 24 de outubro de 2018, que altera a Norma Regulamentadora No 6 - Equipamento de Proteção Individual - EPI”. Brasília, 2018c. Disponível em: https://enit.trabalho.gov.br/portal/images/Arquivos_SST/SST_NR/NR-06.pdf. Acesso em: 24 jul. 2019.

BRASIL. Portaria n. ${ }^{0}$ 3.214, de 8 de junho de 1978, que aprova as Normas Regulamentadoras- NR do cap. V, Título II, da Consolidação das Leis do Trabalho, relativas à Segurança e Medicina do Trabalho. Brasília, 1978. Disponível em: https://enit.trabalho.gov.br/portal/index.php/seguranca-e-saude-no-trabalho/sstmenu/sst-normatizacao/sst-nr-portugues?view=default. Acesso em: 07 jun. 2019.

BRASIL. Ministério do Trabalho. Relação Anual de Informações Sociais-2017. Sumário Executivo, 2017a. Disponível em: http://pdet.mte.gov.br/rais. Acesso em: 19 jan. 2019.

CALVERT, G. M. et al. The prevalence of selected potentially hazardous workplace exposures in the US: Findings from the 2010 National Health Interview Survey. American Journal of Industrial Medicine, v. 56, n. 6, p. 635-646, 2013.

CAMARGO, M. G.; FURLAN, M. M. D. P. Resposta fisiológica do corpo às temperaturas elevadas: exercício, extremos de temperatura e doenças térmicas. Saúde e Pesquisa, v. 4, n. 2, p. 278-288, 2011.

CHAN, A. P. C. et al. Developing a heat stress model for construction workers. Journal of Facilities Management, v. 10, n. 1, p. 59-74, 2012.

GUYTON A. C. Fisiologia humana e mecanismos das doenças. 5. ed. Rio de Janeiro: Guanabara Koogan, 1993.

INTERNATIONAL STANDARDIZATION FOR ORGANIZATION. ISO 7243: hot environments: estimation of the heat stress on working man, based on the WBGT-index (Wet Bulb Globe Temperature). British Standard. Genève, 2017.

INTERNATIONAL STANDARDIZATION FOR ORGANIZATION. ISO 8996: ergonomics of the thermal environment: determination of metabolic rate. Genève, 2004.

INTERNATIONAL STANDARDIZATION FOR ORGANIZATION. ISO 9920: ergonomics of the thermal environment: estimation of thermal insulation and water vapour resistance of a clothing ensemble. Genève, 2009.

JIA, Y. A.; ROWLINSON, S.; CICCARELLI, M. Climatic and psychosocial risks of heat illness incidents on construction site. Applied Ergonomics, v. 53, p. 25-35, 2016.

KROEMER, K. H. E.; GRANDJEAN, E. Manual de ergonomia: adaptando o trabalho ao homem. 5. ed. São Paulo: Bookman, 2005.

LI, X. et al. Evaluating the impacts of high-temperature outdoor working environments on construction labor productivity in China: a case study of rebar workers. Building and Environment, v. 95, p. 42-52, 2016.

MORABITO, M. et al. Might outdoor heat stress be considered a proxy for the unperceivable effect of the ultraviolet-induced risk of erythema in Florence? Journal of Photochemistry and Photobiology B: Biology, v. 130, p. 338-348, 2014.

MORIOKA, I.; MIYAI, N.; MIYASHITA, K. Hot environment and health problems of outdoor workers at a construction site. Industrial Health, v. 44, n. 3, p. 474-480, 2006. 
OCCUPATIONAL HEALTH AND SAFETY COUNCIL OF ONTARIO. Heat stress awareness guide. WSIB Ontario, 2007. Disponível em:

https://www.ohcow.on.ca/edit/files/heatstressawareness/Heat\%20Stress\%20Awareness\%20Guide.pdf. Acesso em: 4 jun. 2019.

OCCUPATIONAL SAFETY AND HEALTH ADMINISTRATION. Heat stress. In: OSHA Technical Manual. Washington, D.C.: Office of Science and Technology Assessment, 1999.

PARSONS, K. Heat stress standard ISO 7243 and its global application. Industrial Health, v. 44, n. 3, p. 368-379, 2006.

PARSONS, K. Occupational health impacts of climate change: current and future ISO standards for the assessment of heat stress. Industrial Health, v. 51, n. 1, p. 86-100, 2013.

RUAS, A. C. Sistematização da avaliação de conforto térmico em ambientes edificados e sua aplicação num software. Campinas, 2002. 196 f. Tese (Doutorado em Saneamento e Ambiente) - Faculdade de Engenharia Civil, Universidade Estadual de Campinas, Campinas, 2002.

SRINAVIN, K.; MOHAMED, S. Thermal environment and construction workers productivity: some evidence from Thailand. Building and Environment, v. 38, p. 339-345, 2003.

WONG, D. P. L. et al. Comparing the physiological and perceptual responses of construction workers (bar benders and bar fixers) in a hot environment. Applied Ergonomics, v. 45, n. 6, p. 1705-1711, 2014.

YI, W.; CHAN, A. P. C. Optimal work pattern for construction workers in hot weather: a case study in Hong Kong. Journal of Computing in Civil Engineering, v. 29, n. 5, p. 05014009-1-05014009-11, 2015.

\section{Adriana Eloá Bento Amorim}

Departamento de Arquitetura e Construção, Faculdade de Engenharia Civil, Arquitetura e Urbanismo | Universidade Estadual de Campinas | Rua Saturnino de Brito, 224, Cidade Universitária Zeferino Vaz | Campinas - SP - Brasil | CEP 13083-889 | Tel.: (19) 3521-2306 | E-mail: adrianaeloa@ufmt.br

\section{Lucila Chebel Labaki}

Departamento de Arquitetura e Construção, Faculdade de Engenharia Civil, Arquitetura e Urbanismo | Universidade Estadual de Campinas | E-mail: lucila@fec.unicamp.br

\section{Paulo Alves Maia}

Escritório Regional de Campinas | FUNDACENTRO | Rua Marcelino Velez, 43, Bairro Botafogo | Campinas - SP - Brasil | CEP 13020-200 | Tel.: (19) 3232-5879 | E-mail: paulo.maia@fundacentro.gov.br

\section{Thais Maria Santiago de Moraes Barros}

Escritório Regional de Campinas | FUNDACENTRO | E-mail: thais.santiago@fundacentro.gov.br

\section{Luiz Roberto Monteiro}

Escritório Regional de Campinas | FUNDACENTRO | E-mail: luiz.monteiro@fundacentro.gov.br

\section{Ambiente Construído}

Revista da Associação Nacional de Tecnologia do Ambiente Construído Av. Osvaldo Aranha, 99 - 3o andar, Centro

Porto Alegre - RS - Brasil CEP 90035-190

Telefone: +55 (51) 3308-4084

Fax: +55 (51) 3308-4054

www. seer. ufrgs. br/ ambienteconstruido

E-mail: ambienteconstruido@ufrgs.br 